\title{
Estratégias históricas: teorias feministas, a história da literatura $e$ a história do cinema nos anos $1970 *$
}

\author{
Pedro Henrique Trindade Kalil Auad**
}

\section{Resumo}

Este artigo trata de algumas das principais questões das teorias feministas dos anos de 1970, a saber, os problemas das histórias literárias e das histórias cinematográficas, do cânone e do valor imputado às obras artísticas. Nesse sentido, busca-se compreender as estratégias adotadas pelas feministas para combater a construção do cânone de então, que não é uma tentativa de destruir o cânone literário ou o cânone cinematográfico, mas um esforço para que seja possível a inclusão de outras histórias a partir de outras epistemologias e, até mesmo, ontologias.

Palavras-chave: História do Cinema, História da Literatura, Cânone, Teoria Feminista.

* Recebido em 12 de setembro de 2014, aceito em 31 de janeiro de 2018.

** Pós-doutorando do Programa de Pós-graduação em Estudos Literários da Faculdade de Letras da Universidade Federal de Uberlândia, Uberlândia - MG, Brasil.pedroauad@gmail.com 
Historical Strategies: Feminist Theory and The History of Literature and The History of Film in The 1970s

\begin{abstract}
This paper addresses some of the major issues of feminist theories of the 1970s: the problem of the history of literature and the history of film, the canon and the imputed value to artistic works. I attempt to understand the strategies adopted by feminists to combat the construction of the canon that is not an attempt to destroy the literary canon or the cinematic canon, but an effort to make the inclusion of other possible histories from other epistemologys and onthologys.
\end{abstract}

Keywords: History of Film, History of Literature, Canon, Feminist Theory. 
Eu sei que o meu passado Eu prestei bem atenção como foi

O presente Eu continuo prestando atenção como

Mas o futuro

Eu não sei como vai ser

É difícil de eu descobrir

Como vai ser o meu futuro.

(Stela do Patrocínio)

Em 1979 é exibida pela primeira vez a instalação artística de Judy Chicago, The Dinner Party. Essa obra é reconhecida como uma das principais das artes feministas dos anos de 1970, especialmente dentre as produzidas nos Estados Unidos: uma mesa em formato triangular, com 39 lugares, cada um deles contendo um prato com formato de vulva - cada qual à sua maneira -, um cálice e um bordado. Doravante, cada um desses 39 lugares é reservado a uma pessoa, todas elas mulheres, como, por exemplo, Isthar, Judite, Trotula, Christine de Pisan, Mary Wollstonecraft, Virginia Woolf. No chão, ainda constam 999 nomes de outras mulheres. A ideia principal da obra de Chicago era "acabar com o contínuo ciclo de omissão em que mulheres foram colocadas para fora do registro histórico" (Chicago, 2007:10). Essa obra, pois, estaria disposta a recontar a história da humanidade, e das mulheres em particular, ao chamar a atenção para essas mulheres que seriam, constantemente, esquecidas; seria o caso de exaltar aquelas que, sem dúvida, foram importantes para a construção da história dos homens e das mulheres.

The Dinner Party exemplifica bem o foco que darei às teorias feministas neste texto: as construções do valor, do cânone e da história da literatura e da história do cinema. Ao se pensar que a valoração das obras é intrínseca às construções dos cânones e da história literária, buscarei colher as estratégias de combate adotadas pelas feministas dos anos de 1970. Aqui se busca afirmar que o que o feminismo realiza não é uma relativização completa e 
irrestrita das formas estéticas - como o senso comum tenta supor, mas um questionamento a respeito dos valores imputados às obras de arte, valores que seriam mais políticos do que puramente estéticos e objetivos.

Focarei aqui as teorias feministas anglo-saxônicas, mas com mais ênfase nas norte-americanas. Não vou me ater às teorias francesas, apesar de saber que a interlocução entre elas é intensa. É na crítica anglo-saxônica que se estabelecem as duas modalidades de combate ao cânone aqui propostas: "tratar de reformular aqueles critérios [estéticos] do interior da instituição acadêmica (...) ou escrever fora dos critérios acadêmicos" (Moi, 1995:37). Reformar os critérios para julgar as obras artísticas faz parte, justamente, da recontagem da história literária e cinematográfica. Essa discussão sobre a história da literatura ea história do cinema, sob a ótica feminista, pode parecer uma discussão antiga ou mesmo ultrapassada. Entretanto, Caitlin Fisher irá pensar em algo que ela denominou de retrofeminismo, isto é, um feminismo que parece renascer com as mesmas problemáticas de antigamente, ou, em suas palavras quando observava as novas feministas, "era como o The Dinner Party, de Judy Chicago, de novo" (Fisher, 2008:148). De fato, estratégias feministas "antigas" são recapituladas hoje, como, por exemplo, a Marcha Mundial das Mulheres que "mudou", por um dia, o nome de logradouros públicos em Belo Horizonte, substituindo os nomes de homens por de mulheres, como a Praça Rio Branco que foi rebatizada por Praça Pagu.

Fisher não afirma que esse retrofeminismo é um problema, pelo contrário, ela afirma que essas imagens do passado feminista no presente

discutem tanto sobre o passado do feminismo quanto sobre o presente, são capazes de serem lidas como ingênuas $e$ como frescas, perigosas e produtivas, rompem com o conto do desenvolvimento fácil linear do feminismo de antes para o feminismo de agora, e fazendo isso revelam novas possibilidades, (...) novas maneiras sugestivas para se 
pensar sobre quem "nós" achamos que somos e aquilo que carregamos dentro de nós (Fisher, 2008:148). ${ }^{1}$

Se os problemas do "passado" feminista ainda são pertinentes ao presente, considero também que as discussões pontuais sobre a história literária e a história cinematográfica ajudam a iluminar a discussão sobre as teorias literárias e as teorias cinematográficas contemporâneas $e$ as estratégias históricas.

A problematização da história literária e, posteriormente, da história cinematográfica, entretanto, não é nova $e$ não foi inaugurada pela teoria feminista. No Brasil, por exemplo, antes mesmo das construções das teorias modernas da literatura, havia proposições nesse sentido, nem sempre convergentes, de Silvio Romero e José Veríssimo ${ }^{2}$, entre outros. Os formalistas russos refletiram sobre a problemática da história literária, como é possível conferir no texto Da Evolução Literária, de Tynianov; no mundo anglo-saxão há o clássico texto de T. S. Eliot, Tradição e Talento Individual. Enfim, o problema da construção da história literária e do cânone posa como um dos principais dos estudos literários há muitos anos.

A teoria feminista, dessa forma, se coloca dentro de uma certa continuidade na discussão das questões do cânone e da história, suas inclusões e exclusões, mas propondo uma nova abordagem, em um movimento de continuidade/descontinuidade. A descontinuidade se dá não por questionar os procedimentos ou métodos empregados na construção da história literária, mas por colocar em xeque os critérios estéticos do leitor, que incluiriam ou não uma determinada obra nessa história. O ponto de partida para essa abordagem da problemática histórica se dá pela constatação da exclusão de muitas mulheres das principais histórias literárias e histórias cinematográficas.

\footnotetext{
1 A tradução deste trecho, como os demais provenientes de língua estrangeira sem indicação de tradução na bibliografia, foram realizadas pelo autor do texto.

2 Para uma reflexão sobre esses dois autores conferir Rocha (2013) e Malard (2013).
} 


\section{A História (da literatura) sob uma nova perspectiva}

O problema do cânone literário (e do cânone cinematográfico) e da história literária (e da história cinematográfica) ganha novos contornos a partir da denominada segunda onda feminista. Isso não exclui, obviamente, o tratamento que a questão teve anteriormente, como é possível ver no clássico $A$ Vindication of the Rights of Women [Em defesa dos direitos da mulher], de Mary Wollstonecraft. ${ }^{3}$ Porém, há uma mudança de postura em relação à lógica de Wollstonecraft $e$ as feministas da segunda onda. Enquanto a primeira acredita que as mulheres não entraram na história oficial ao serem impedidas de ter uma formação como a dos homens, as novas feministas afirmam que mesmo aquelas que mereceriam espaço não o teriam porque a história destaca os homens, não as mulheres. Ou seja, não é importante somente revelar que as mulheres foram excluídas de processos que as levariam a pertencer à construção histórica, como também se ressalta que mesmo aquelas que adentraram nesses processos foram excluídas da história oficial.

Será muito cara ao feminismo essa recontagem. Recontar, aqui, pode ser entendido em dois sentidos: quantitativo $e$ qualitativo. Entretanto, qualitativamente se mostra ainda mais preponderante em exemplos do que quantitativamente. Ademais, mesmo quando a contagem se pauta por ser quantitativa, o objetivo final é qualitativo. Não me alongarei em exemplos, mas,

3 A escolha desse texto se dá por ser classificado como o que inaugura o feminismo moderno, ou o que doravante foi denominado como "first wave feminism" (Cf. Sanders, 2000:16). Ademais, esse talvez tenha sido o primeiro texto a realmente provocar uma polêmica na sociedade e ser discutido amplamente. Constância Lima Duarte (1989:106) frisa a repercussão que a obra causou em sua época: "Este texto revolucionário, surgido em Londres em 1792, foi imediatamente traduzido para o francês e repercutiu como uma bomba em toda a Europa e até nos Estados Unidos. Neste mesmo ano, ele foi também editado em Paris, Boston e Filadélfia e teve ainda sua segunda edição em Londres. Em Dublin, foi editado em 1793 e, na Filadélfia, duas novas edições surgiram no ano de 1794. No curto espaço de dez anos, o livro foi reeditado sete vezes, na França, na Inglaterra, nos Estados Unidos e na Escócia”. 
quantitativamente, podemos verificar os trabalhos das Guerrilla Girls, grupo de artistas feministas anônimas que iniciaram suas obras em 1985, em Nova Iorque. Em seus trabalhos Do women have to naked to get into the Met. Museum? a ideia é quantificar as artistas mulheres e o número de corpos nus expostos no Metropolitan Museum, de Nova Iorque, na seção de arte contemporânea. A questão é: "É preciso a mulher estar nua para entrar no Metropolitan Museum?". É por meio da quantificação das obras que se qualificaria o museu, ou seja, mesmo quando a premissa é quantitativa, a finalidade passa a ser qualitativa. A simples pergunta é uma forma de colocar vários problemas: a representação feminina (os corpos nus predominantemente femininos); o espaço discursivo "permitido" às mulheres (as poucas artistas mulheres); e, consequentemente, os valores tradicionalmente machistas que representariam as mulheres nas artes (não é a sua própria expressão, mas seu corpo nu).

Alguém poderia se perguntar: mas isso não se dá pelo fato de grande parte dos artistas contemporâneos serem homens? Não seria porque os "grandes" são todos homens? A partir dos anos 1970, no mínimo, o número de artistas mulheres (aqui não incluo somente as feministas) é crescente. Incentivadas pelo feminismo, ou por sua colocação em "mercados" semelhantes aos dos homens, muitas mulheres artistas surgiram, o que deveria ter levado a uma diminuição desse abismo. ${ }^{4}$

No sentido estritamente qualitativo podemos recuar até o século XIX, com Lucy Parsons (1853-1942), por exemplo - exescrava, feminista, anarquista e agitadora política e cultural, uma das fundadoras da organização sindicalista revolucionária Industrial Workers of the World (IWW) - que foi presa por seus escritos provocadores no jornal anarquista de Chicago, The Liberator. Neste jornal, em 1905, Parsons concebeu e criou uma coluna que teria como motivação escrever a história de mulheres importantes e negligenciadas. Ela afirma:

\footnotetext{
4 Também em Nova Iorque, o Museu do Brooklyn abriu uma seção de arte feminista em 2012.
} 
Debaixo do cabeçalho acima continuaremos, por algumas semanas, com pequenos esboços de mulheres que tenham contribuído com sua parte na construção da história do mundo. Enquanto a editora irá contribuir com alguns desses esboços, nós também convidamos, especialmente as mulheres, a nos mandar breves esboços de mulheres famosas, se alguma vier à cabeça. Façam com que esses esboços sejam bem específicos, curtos e diretos ao ponto. Nós esperamos que se algum for mandado, eles serão muito superiores aos que nós mesmos escrevermos (Parsons, 2004:105).

Parsons escreve, então, uma coluna - a primeira de uma série - sobre Florence Nightingale, coordenadora de um hospital de guerra que deveria ser lembrada "como uma mulher que, ainda que delicada e destituída de muito de sua vontade, estava disposta a arriscar a própria vida para que pudesse levar alívio para a vítima mais estúpida do nosso presente sistema, o soldado" (Parsons, 2004:107). É na requalificação da participação histórica das mulheres que esse procedimento qualitativo operará. ${ }^{5}$

Podemos ainda dar, como outro exemplo, o texto da escritora Alice Walker, Saving the life that is your own: the importance of models in the artist's life, que também reflete sobre a exclusão das mulheres do cânone e da história. No caso do texto de Walker, a exclusão das mulheres negras em particular. A escritora afirma que, em sua época de colégio, ela não tinha ouvido falar em nenhuma escritora negra e se perguntava se existiria alguma. Após o colégio, Walker (1997:31) continuava a se perguntar: "onde estão os pesquisadores de folclore negros? Onde está o antropólogo negro?" e assim por diante. Walker, pois, se prontificou a estudar a história das mulheres negras elididas do cânone. Como resposta ao questionamento de só se interessar por escritoras negras, ela afirma: "nós nos importamos porque nós

5 Poder-se-ia, ainda, relatar essas estratégias históricas dentro de outros campos predominantemente masculinos, como as ciências "duras" (Cf. Tabak, 2002) ou mesmo na música pop, como é o caso do punk-rock (Cf. Hanna, 2007). 
sabemos isso: a vida que salvamos é a nossa própria" (Walker, 1997:31 grifo da autora). Reconstruir uma história das mulheres em geral, e das mulheres negras em particular, seria também uma forma de Walker se incluir em uma nova história, a partir daí contada. Muda-se o presente quando se muda o passado e viceversa.

Nesse sentido, pensar a história se torna imperativo ao feminismo por uma série de motivos. O primeiro, para pensar em por que as mulheres foram sistematicamente excluídas da participação social; o segundo, para restituir às mulheres lugar importante na história da humanidade; terceiro, para que daí a participação das mulheres seja cada vez mais incisiva.

É em meio a essas elaborações que trabalhará, também, a teoria da literatura feminista, como no caso do emblemático texto de Annette Kolodny, Dancing through the minefield, de 1980, no qual irei me deter mais calmamente. Nesse texto, a crítica novaiorquina constata que, dez anos antes, haveria uma "inadequação das escolas críticas estabelecidas e dos métodos para lidar de forma justa ou sensível com os trabalhos escritos por mulheres" (Kolodny, 1997:171). Kolodny acredita que a função da crítica literária não seria apenas mostrar o sexismo nas obras artísticas, mas também marcar as novas escolhas na história literária:

Para aquelas de nós, da literatura americana especialmente, o fenômeno prometeu uma reformulação radical de nossos conceitos de história literária e, pelo menos, um novo capítulo para entender o desenvolvimento das tradições literárias das mulheres (...) nós inevitavelmente levantamos questões desconcertantes sobre as razões para o desaparecimento [da literatura das mulheres] nos cânones dos "principais trabalhos", e nós nos preocupamos com a estética e os critérios críticos pelos quais se estabeleceu a diminuição do seu status (Kolodny, 1997:172).

Para Kolodny, os homens - professores e acadêmicos, inclusive -, quando entram em contato com a literatura de autoria 
feminina, não conseguem compreender o universo simbólico da mulher. A crítica à academia é ainda mais particularizada:

Ao invés de serem bem-vindas ao trem, entretanto, nós temos sido forçadas a negociar em um campo minado (...) se nós somos acadêmicas dedicadas a redescobrir um corpus perdido de textos escritos por mulheres, nossos achados são questionados esteticamente. $\mathrm{E}$, se nós somos críticas determinadas a praticar leituras revisionistas, é dito que nosso foco é muito estreito, e que nossos resultados são apenas distorções de, ainda pior, más interpretações polêmicas (Kolodny, 1997:175).

Kolodny afirma que, com o feminismo, o que muda não é o fim de uma tradição ocidental, mas sim o eclipse de uma forma particular de texto, de um modelo particular de cânone, cujo leitor-modelo seria masculino com seu senso e significado de mundo. O cânone, pois, seria um problema em si:

o fato de a canonização colocar trabalhos acima de qualquer questão acerca do estabelecimento de seus méritos leva os estudantes a oferecerem leituras e interpretações apenas mais ingênuas, com o propósito de validar os grandes já canonizados (Kolodny, 1997:176).

A autora, pois, tece três proposições a respeito do cânone: 1) a história literária é uma ficção; 2) o que se ataca não são os textos, mas sim os paradigmas; 3) o reexame não é somente da estética, mas também dos preconceitos e pressupostos do cânone, sendo necessário informar os métodos críticos que moldam as respostas estéticas.

Kolodny argumenta, a respeito do primeiro ponto, que a história literária é uma construção ficcional; em outras palavras, a história literária é uma história contada, e não um objeto estático ou imanente. Para Kolodny e as feministas em geral, a história seria sempre contada como uma visão masculina da arte, que embutiria qual história ela conta: a história literária dos homens. 
Ora, as escolhas do presente, argumenta a crítica, inevitavelmente, alteram as do passado:

O que distingue as feministas nesse aspecto é o seu desejo de alterar $e$ estender o que entendemos como historicamente relevante a partir desse vasto depósito da nossa herança literária e futuro reconhecimento feminista do depósito pelo que ele realmente é: uma fonte para remodelar nossa história literária, passado, presente e futuro (Kolodny, 1997:178).

A respeito do ataque aos paradigmas que levariam à afirmação de determinada história literária, a autora afirma que as estratégias críticas que aprendeu primeiramente davam importância ao o quê se lê como oposto ao como se aprendeu a ler. Como se ler uma obra implicasse sempre em o quê se lê dela. Como as mulheres e os homens sempre foram ensinados a ler de uma determinada maneira, o que se leria também seria correspondente a essa maneira previamente aprendida. Com as teorias desenvolvidas por homens, o que se estudaria em obras das mulheres seria sempre na perspectiva masculina. Dessa forma, as mulheres sairiam do mapa principalmente por "uma incapacidade de predominantemente criar leitores para interpretar e apreciar textos de mulheres - devido, em grande parte, a uma falta de conhecimento anterior" (Kolodny, 1997:179).

Quanto ao terceiro e último ponto, Kolodny argumenta que

críticas literárias feministas estão essencialmente procurando descobrir, em primeiro lugar, como os valores estéticos são atribuídos [e] qual validade pode realmente ser afirmada pelos nossos "julgamentos" estéticos (Kolodny, 1997:181).

Em outras palavras, entram em jogo quais concepções de mundo e quais ideologias esses valores estéticos perpetuam, sua relação com o valor atribuído a uma determinada obra e não a outra. Para Kolodny, "o que aparenta ser uma disputa por mérito 
estético é, na verdade, uma disputa pelo contexto de julgamento" (Kolodny, 1997:182 grifo da autora). A teórica, enfim, determina o ponto em que a crítica feminista deveria agir e contra quem:

colocando de forma direta: nós tivemos um número suficiente de pronunciamentos sobre avaliação estética há um bom tempo; é agora nossa obrigação avaliar as normas imputadas e os jargões normativos de leitura que, em parte, levaram a esses pronunciamentos (Kolodny, 1997:182).

A crítica nova-iorquina reconhece o pluralismo das abordagens feministas - estruturalistas, psicológicas e até formalistas, percebendo que essas abordagens oferecem leituras mais ou menos ricas e estratégias mais ou menos apropriadas. Porém, essa ordem diversa de abordagens não é vista de maneira negativa, e assumir o pluralismo não é assumir o desacordo, mas a

possibilidade que leituras diferentes, ainda que do mesmo texto, possam ser úteis à sua maneira, até mesmo iluminadoras, dentro de diferentes contextos de investigação. Isso significa, de fato, que nós entramos em um processo dialético de examinar, testar, e mesmo experimentar os contextos (Kolodny, 1997:184).

Esse processo dialético revelaria qual é o processo crítico, como ele funciona, acessando possibilidades futuras de investigação $e$ discutindo o que pode ser realizado de maneira diferente.

Kolodny argumenta que somente o compromisso ideológico levou as mulheres a entrar no campo minado dos estudos literários, colocando em perigo suas carreiras e subsistência. Ela defende a ideologia como dissipadora de energias reprimidas $e$ que ela poderia "admitir objetivos críticos que, uma década atrás, teriam sido abandonados em desespero ou apatia" (Kolodny, 1997:185), e afirma que "se a crítica feminista coloca alguma coisa em questão, deve ser o mito dogmático da neutralidade intelectual" (Kolodny, 1997:186). De maneira contundente, ela 
afirma que a neutralidade não existe, e que as implicações críticas canônicas e de valor são determinadas, de uma maneira ou de outra, pelo contexto do crítico. Ela defende que a luta ideológica das mulheres deve acontecer, pois "ideias são mais importantes porque elas determinam a maneira que nós vivemos, ou queremos viver, no mundo" (Kolodny, 1997:186 grifo da autora).

Kolodny, dessa forma, resume uma das inquietações iniciais da segunda onda feminista: o lugar da mulher e a construção de uma história que excluiria não somente obras femininas, como também a forma de se expressar como mulher. A questão da formação do cânone ganha novos contornos àquela época sob esse viés: a seleção de textos não se daria somente com a escolha de "grandes" obras que, por certos valores estéticos, são representadas pela história, mas também questionando quais são esses valores estéticos e quais são as suas implicações ideológicas.

Assim, a autora coloca duas premissas que, considero, são essenciais nessa perspectiva: como se lê e o contexto de julgamento de uma obra. Na primeira, está implicado que a forma que se lê uma obra corrobora certas perspectivas que estariam engajadas, pelo leitor, nesse processo. O como contém, em sua essência, valores ideológicos que são reproduzidos na sociedade e são sustentados pelo crítico na avaliação de uma determinada obra. Para entender esse processo, seria necessário desvelar o contexto de julgamento em que essas obras foram avaliadas. $\mathrm{O}$ feminismo, pois, teria essa dupla função: revelar a ideologia por trás da valoração de uma determinada obra, ao mesmo tempo que se empenha em pensar novas maneiras de como se lê uma obra, inserindo aí uma visão da mulher que represente também sua ideologia e não excluindo ainda outras análises possíveis a partir de outros contextos de julgamento.

Como solução para impasses ideológicos e de abordagens diferentes, Kolodny afirma que é através do pluralismo, mas sem perder a fricção, que se poderia ter uma ampla resposta ao problema literário. Não seria mais uma questão de qual a melhor forma metodológica ou epistemológica de abordar o literário como o todo, mas sim de que forma determinada abordagem 
contribui para a nossa leitura de determinados textos. Essas leituras plurais ajudariam a pensar não só o mundo em que vivemos, mas também aquele mundo em que se quer viver.

Aqui, claro, não se encena uma disputa entre uma crítica subjetiva e uma crítica objetiva. O que se quer desvelar é que o forjar de uma crítica supostamente objetiva no discurso ainda deixa transparecer traços subjetivos. Não é o caso de excluir qualquer tipo de objetividade, mas deixar a subjetividade mais clara possível, e ter a sapiência de que, mesmo com o maior dos esforços, algo da subjetividade ainda virá à tona. Daí que se inseriria a questão de valores que estão engajados na leitura e na avaliação de um texto: os valores tidos como positivos e ensinados enquanto tal seriam reproduções daqueles controladores do contexto de julgamento.

A crítica feminista, entretanto, não só irá questionar esses valores, mas também se empenhará a discutir e propor novos. Dessa forma, a história literária e o cânone se tornariam processos dinâmicos, e não estáticos, ou, melhor dizendo, se tornariam ainda mais dinâmicos, porque, de alguma forma, a história literária e o cânone nunca foram, de certo, um monólito. Aqui se acentua esse processo, dando um foco não só na obra, mas também no contexto de julgamento de uma obra e da teoria, isto é, desvela-se o domínio, por um determinado grupo, desse contexto.

É importante ressaltar, ainda, que a crítica feminista irá não somente resgatar textos antigos "esquecidos" pelo cânone $e$ reavaliá-los - como, por exemplo, a monumental obra de Zahidé Lupinacci Muzart, Escritoras brasileiras do século XIX (1999)-, como também irá incentivar a literatura realizada por mulheres, chegando a pensar em uma escrita feminina - écriture féminine como proposto por Hélène Cixous. A reconstrução do cânone literário não perpassaria somente por resgatar obras, como também por propor novas obras, ou seja, se criaria, também, o presente dessa história.

Antes de prosseguir nessa argumentação, exponho, a seguir, como a teoria do cinema feminista trabalhou com esse problema, 
que é acentuado já que, até então, havia poucos filmes realizados e dirigidos por mulheres.

\section{Teoria do cinema feminista}

Certos processos questionados por Kolodny para a história da literatura também o são para a crítica e a teoria do cinema, como demonstra B. Ruby Rich em Chick Flicks. Este livro, uma espécie de "atentado contra a amnésia histórica", descreve

o amplo campo do feminismo e dos filmes que começou nos anos 1970 com o florescer de festivais de filmes e a simultânea invenção de aproximações teóricas a clássicas representações de mulheres de Hollywood, eventualmente se expandindo para outros filmes também. É uma disciplina que começou como um movimento, retirando sua força das rupturas políticas do movimento de libertação das mulheres como também das lições intelectuais e ideológicas da Nova Esquerda (Rich, 2004:1-2).

O livro explora os primeiros esforços de prática feminista no cinema dos Estados Unidos, sendo que um dos pontos principais seria a luta contra cineastas que bradariam por um estruturalismo masculino, que definiam os filmes das mulheres - e particularmente da cineasta Carolee Schneemann - como pessoais, sentimentais, indulgentemente diarísticos, com uma gestalt densa e técnicas primitivas. Essa cineasta seria paradigmática, como descreve a autora, porque desafiaria as velhas lógica e premissa do distanciamento artístico.

Interessa-nos, aqui, realçar a importância dos festivais para reavaliar a história do cinema, incluindo aí as cineastas negligenciadas. ${ }^{6}$ Os primeiros grandes festivais na América do Norte, relata Rich, aconteceram em 1972, em Nova Iorque, e em 1973, em Montreal, como uma aparição pública do feminismo.

${ }^{6}$ Robert Stam (2009:194) também afirma que "as primeiras manifestações da onda feminista nos estudos de cinema ocorreram com o surgimento dos festivais de cinema de mulher (...) em 1972". 
Eles não estavam interessados somente em mostrar "bons" filmes ou filmes selecionados, seja pela temática ou por autores; eles conteriam a "mensagem do dia" e teriam, sobretudo, uma missão. Para uma jovem geração, nascida na contracultura, os festivais de cineastas mulheres

eram laboratórios experimentais, produzindo uma nova
consciência feminista cinemática enquanto
simultaneamente colocava também em prática o
comprometimento político por trás das atividades. (...)
Todo processo de planejamento seria inevitavelmente
também um processo político. (...) Toda decisão era
carregada de ideologia (Rich, 2004:31).

Esses festivais se apresentavam como um processo humanizador ao afirmar que o cinema é um processo humano. Eles também seriam contra uma construção estereotipada do feminino e o único critério para a seleção de filmes seria o de serem realizados por mulheres, com o argumento de que cada uma poderia ter sua própria opinião de o que seria um cinema feminista. Ademais, os festivais tinham sempre uma questão ideológica: "as questões centrais eram a respeito de até onde diretoras mulheres apresentaram uma crítica da sua posição na sociedade, ou, alternativamente, até onde elas apenas refletiram a ideologia dominante" (Rich, 2004:33). O cinema e os festivais, pois, teriam como base um conflito ideológico, afirmando-se contra uma visão desumanizada da mulher.

Esses festivais tinham como objetivo

o encargo de criar um espaço sem precedentes para o cinema de mulheres, tanto na imaginação quanto no palácio do filme, que levou a essa filosofia de inclusão; foi depois, com as carreiras acadêmicas em jogo, que as linhas estéticas de demarcação foram desenhadas e executadas (Rich, 2004:35). 
Somente depois dos festivais é que se começa a demarcar as linhas de diálogo entre estética, forma e política feministas. Portanto, independentemente da abordagem epistemológica que as críticas e teóricas utilizavam, a pauta seria recontar a história. Como ainda não havia muitas diretoras consagradas no cinema, era preciso "criar" os clássicos feministas. Na recontagem da história cinematográfica alguns nomes surgiam: Maya Deren, Agnes Vardà, entre outros ${ }^{7}$, mas seria preciso ir além de nomes e construir uma maneira, não só de mulheres, mas feminista, de se fazer cinema.

O olho do furacão da recontagem da história pode ser identificado em Leni Riefenstahl, a cineasta favorita de Adolf Hitler, que teria sido expurgada da história por seus filmes nazistas. É curioso atestar que, por outro lado, Griffith e seu filme imensamente racista, $O$ Nascimento de Uma Nação, seriam um clássico condecorado pela história do cinema, sem nenhuma, ou quase nenhuma, ressalva. Rich, em sua reanálise de 1979, afirma que

os pecados de Riefenstahl no reino da estética são os mesmos pecados de Hollywood, Moscou, China, Índia, Egito, Europa - de todo lugar do mundo onde a noção de representação da realidade é a base para o cinema e o objetivo de controlar a resposta da audiência é a fundação da ideologia (Rich, 2004:45).

Ela acredita que a cineasta alemã é exemplo não só por corroborar com o pensamento nazista, como também por representar a subordinação feminina, que aceitaria a estrutura patriarcal daquele período da Alemanha. Ademais, o "pecado" de

\footnotetext{
7 Poderia citar também alguns filmes que, até então, já haviam sido lançados como Die Abenteuer des Prinzen Achmed (1926), de Lotte Reiniger; Mädchen in Uniform (1931), de Leontine Sagan e Carl Froelich; O Ébrio (1946), de Gilda de Abreu; Khaneh siah ast (1963), de Forugh Farrokhzad; Älskande pa (1964), de Mai Zetterling; Sedmikrásky (1966), de Vera Chytilová; Portrait of Jason (1967), de Shirley Clarke; Wanda (1970), de Barbara Loden; entre outros.
} 
Riefenstahl, segundo a visão de Rich, seria, próximo das teorias da montagem soviéticas, que tinham como um dos seus objetivos o aperfeiçoamento do controle da audiência.

Entretanto, a crítica estruturada feminista do cinema surgiria não só depois dos festivais citados acima, mas também depois de filmes que articulariam essa crítica: "a fertilização mútua inicial entre o movimento das mulheres e o cinema, que teve lugar na área prática mais do que escrevendo críticas: os filmes vieram primeiro" (Rich, 2004:65). Essa posição é defendida por Rich: a sustentação densa teoricamente do feminismo no cinema, pois, necessitava, primeiramente, de uma construção de filmes, de objetos. Os filmes feministas começaram a surgir intermitentemente junto aos festivais de cinema organizados $e$ focados nas mulheres, tendendo a ser muito mais ligados a uma tradição avant-garde do que ao esquema hollywoodiano. Não somente pessoais/experimentais, eles seriam ligados a um

movimento político envolvente [que] deu ao cinema feminista um poder e uma direção inteiramente sem precedentes em filmes independentes, trazendo questões de teoria/prática, estética/significado, processo/interpretação com um foco incisivo (Rich, 2004:63).

Um dos filmes mais representativos dessa época estimulante para o cinema feminista é Jeanne Dielman, 23 Quai du Commerce, 1080 Bruxelles, de Chantal Akerman, lançado em 1975. Ele foi o primeiro filme a

escrutinar o trabalho de casa com uma linguagem apropriada, mostrando as atividades de uma mulher em casa em tempo real para comunicar a alienação das mulheres no núcleo familiar sob as condições econômicas da Europa pós-guerra (Rich, 2004:67).

Dessa forma, a história do cinema feminista tomou duas direções: a primeira, construindo uma história de filmes realizados por mulheres, independente do tema e da ideologia ali reinante; $e$ 
a segunda, produzindo filmes que corroborariam com as premissas ideológicas e críticas do feminismo.

Rich irá observar que a primeira revista de cinema feminista realmente empenhada em utilizar ferramentas contemporâneas da teoria foi a Camera Obscura, que refletiu sobre essa história dos cinemas das mulheres nas duas vias, isto é, tanto no resgate histórico dos filmes quanto nas propostas de um cinema feminista.

A primeira edição da revista Camera Obscura foi organizada e escrita pelo Camera Obscura Collective, composto por Janet Bergstrom, Sandy Flitterman-Lewis, Elisabeth Hart Lyon e Constance Penley e foi financiada pela Universidade de Berkeley, mas não constava como publicação oficial da universidade. Todos os textos escritos para a primeira edição da revista e a tradução do texto de Jean-Louis Baudry, The Apparatus, foram assinados coletivamente, sem distinção autoral. A exceção a essa regra foi a seção Women Working, escrita por Christina Creveling, e a introdução ao texto de Baudry, citado acima, feita por Bertrand Augst e Francis M. Cornford. Nessa primeira edição, o coletivo de autoras pretende estabelecer critérios que ajudariam a delimitar o que poderia ser chamado de crítica feminista do cinema. É no texto Feminism and Film: Critical Approaches que essas reflexões são mais acentuadas e/ou destacadas. $\mathrm{O}$ texto começa informando quais são as perspectivas teóricas que a revista busca empreender:

O periódico Camera Obscura foi envolvido pelo reconhecimento da necessidade do estudo teórico do cinema, neste país, com uma perspectiva feminista $e$ socialista. Esse tipo de análise reconhece que as mulheres são oprimidas não só economicamente e politicamente, mas também na própria forma da razão, do significar e na troca simbólica da nossa cultura. O cinema é um lugar privilegiado para o exame desse tipo em sua conjectura única de códigos políticos, econômicos e culturais (Camera Obscura Collective, 1976:3).

É importante ressaltar nessa citação o caráter político ou, em outras palavras, o engajamento, não só teórico, inerente à teoria 
feminista. Ao lado de outras lutas históricas das mulheres - por posições igualitárias na esfera econômica, por exemplo - há ainda um destaque para que se construa também uma posição de igualdade entre homens e mulheres no que concerne aos estudos cinematográficos, que, consequentemente, se entranhariam em outros campos dos discursos simbólicos. Ou seja, não é só uma questão de fazer uma crítica ou teoria feminista, mas que, através dessa teoria, o campo simbólico da sociedade se transforme. De certa forma, essa proposição ainda endossa a proposta de Kolodny, ao afirmar que o significar tem que ser repensado, ou seja, que a maneira pela qual significamos (e como somos levados a significar), se torna também importante para estabelecer um novo tipo de crítica, nesse caso, a feminista.

Dessa forma, fica claro que o contexto da formulação teórica da revista não se restringe a disputas empíricas de um determinado campo, isto é, não é só uma questão de incluir autoras femininas ou feministas (seja como teóricas, seja como autoras de um corpus de estudo) - que é indispensável -, mas também, e principalmente, que as disputas aconteçam no campo simbólico, da razão e da significação da cultura. Enfim, não se advoga só a inclusão das mulheres, mas também sua participação na construção do imaginário político-social. Sendo assim, a teoria que a revista desenvolverá é um processo de construção política, de engajamento, de combate dentro do campo simbólico.

Mas como esse engajamento é possível, ou, melhor dizendo, como a teoria feminista do cinema poderia se aliar à práxis? As autoras afirmam que o que seria "crucial para a luta feminista é a conscientização de que qualquer teoria de como mudar a consciência requer uma noção de como a consciência é formada, do que é a mudança e como ela ocorre" (Camera Obscura Collective, 1976:3). O coletivo de autoras entende que a mudança simbólica que a luta feminista anseia só pode acontecer se for possível conhecer os processos pelos quais esse simbólico é construído e perpetuado. Não bastaria apenas agir contra as desigualdades da sociedade, é necessário saber de onde elas vieram, como se construíram e como elas são retroalimentadas. 
De alguma forma, revela-se assim a velha tentativa de aliança entre a práxis e a teoria. Reconhecendo que a luta sem um embasamento pode se tornar vazia e que a teoria enclausurada pode se tornar etérea, a revista promulga que o reconhecimento teórico é alicerce para a prática. Esse processo se tornaria ainda mais imprescindível por se tratar das disputas em campos simbólicos, e lidar com essas disputas justificaria a perspectiva teórica adotada pela revista: a análise textual, junto à semiologia $e$ à psicanálise. Nessa perspectiva, o próprio filme é um centro de embates simbólicos e a análise textual ajudaria a perceber todos os processos abertos pelo jogo entre cineasta, filme e espectador.

Aqui, é importante notar que as imagens são entendidas como texto, como discurso, e é esse discurso que será arduamente analisado. Com certa inspiração em textos feministas anteriores, principalmente Visual Pleasure and Narrative Cinema, de Laura Mulvey, o Camera Obscura Collective, percebe que o que está em jogo não é apenas uma visão de um determinado cineasta se dirigindo a um determinado público: são discursos sociais diversos que se entrecruzam em todo o processo fílmico (da produção à exibição), ou seja: do cineasta ao espectador há um emaranhado de construções simbólicas que são colocadas em jogo, sejam conscientes ou inconscientes.

Nesse sentido, começa a formação de um conjunto de filmes dirigido por mulheres. É necessário, ao mesmo tempo, enunciar esses filmes, falar que eles existem e também começar a analisálos. Em busca de formular um catálogo de filmes feministas $e$ dirigidos por mulheres, a revista empreende uma busca por essas diretoras, fazendo a análise do filme experimental Deux Fois, de Jack Raynal, e sobre o trabalho da diretora Yvonne Rainer. Rainer também é uma diretora de filmes experimentais minimalistas, e, ao analisar a abrangência que seus filmes terão, talvez a revista revele a expectativa que ela mesma coloca em si:

que os filmes de Rainer serão vistos apenas por uma audiência limitada e seleta é obvio; mas não é obvio que isso não exclui seus filmes de ter um impacto político 
válido. Mesmo que só influenciando um pequeno número de vidas é importante, sem mencionar a influência direta que seus filmes podem ter naqueles que não a verão no trabalho de cineastas, artistas, escritores, e outros que tenham visto e tenham sido influenciados por ele (Camera Obscura Collective, 1976:3).

Aqui, é importante ressaltar que a teoria feminista do cinema é posterior - como também afirma Rich - a uma produção fílmica que elucidaria as propostas teóricas - e a Camera Obscura iria construir suas teorias paralelamente a filmes contemporâneos. Mas isso não descartaria que, ainda assim, acontecesse um resgate de filmes que, a partir dali, seriam considerados como feministas. Quem assume esse encargo é a coluna Womem Working, conduzida por Christine Creveling. O espaço dessa coluna seria justamente para divulgar filmes realizados por mulheres cineastas, não necessariamente concomitantes com a revista, isto é, em um resgate dessas mulheres e uma construção dialógica entre as propostas teóricas feministas que tentavam elucidar na revista $e$ aqueles filmes ali selecionados. Na primeira edição da revista, cineastas como Anne Severson, Babette Mangolte, Kathleen Laughlin, Dore O., Chantal Akerman são brevemente apresentadas, seguidas por uma curta descrição de seus filmes.

\section{Estratégias}

A recontagem da história literária e cinematográfica e o valor dado às obras, como alertam Kolodny, Rich e a Camera Obscura, podem ser feitos por diversos meios: a) enumerando qualquer obra que tenha sido produzida por mulheres; b) reavaliando a qualidade das obras de mulheres que estariam fora da história; c) estabelecendo novos critérios para avaliar essas obras, já que obras diferentes pressuporiam métodos e valoração diferentes; d) questionando os critérios estabelecidos, por meio do desvelamento da ideologia por trás da metodologia da escrita da história literária ou cinematográfica; e) recontando a história com novos critérios e valores, em uma posição contraideológica, isto é, 
"desafiando" os valores masculinos e do patriarcado; f) realocando velhas teorias dentro de novas perspectivas, destacando o contexto de julgamento; g) como uma positivação do termo ideologia para se travar uma luta, justamente, ideológica; h) levando as disputas ao campo simbólico e da significação da cultura; i) reconstruindo o passado com uma produção incessante de obras feministas no presente.

Tanto a teoria da literatura quanto a teoria do cinema desenvolveram uma mesma estratégia: reavaliar as obras das mulheres, incluindo aí novos índices de valores, desvelando o lugar em que se localizavam os antigos críticos e teóricos que elidiram as obras das mulheres da história. O que Vera Queiroz observa sobre o texto de Kolodny, pois, pode ser expandido para os outros textos aqui discutidos:

No aspecto particular da formação dos cânones e da historicidade do literário, o historiador e o crítico, mais do que um lugar definido a partir do qual resgata o passado, o organiza e o avalia, têm também a configurar-lhe a visão suas circunstâncias de classe, sua inserção racial e seus preconceitos de gênero. Negar isso seria conferir à história literária uma isenção e uma neutralidade incompatíveis com as perspectivas de mobilidade e dinamicidade que configuram hoje o domínio da história (geral), a compreensão dos lugares ocupados pelo sujeito e pelo conhecimento contemporâneos (Queiroz, 1997:39).

Nesse sentido, fica claro que, para o pensamento feminista, a questão não é destruir o cânone, mas repensá-lo, questioná-lo, tentar entender as suas motivações e seus preconceitos; o mesmo pode ser dito, de certa forma, sobre a própria teoria: ao pegarem emprestados diversos aspectos de outras correntes teóricas, as teorias feministas reconstroem o jogo teórico a partir de algo já dado, mas com uma nova abordagem e com novos elementos. É a partir daí - dos objetos e das teorias - que se propõem novas abordagens e novos valores que poderiam ser também utilizados para a avaliação de uma determinada obra. 
Ora, aqui se trata de colocar em jogo outros atores para a avaliação de uma determinada obra e deixar ainda mais dinâmica a história literária, fazendo com que valores díspares entrem em choque, não reproduzindo somente um determinado valor de uma ideologia dominante. É certo que cada história literária reflete os valores de uma determinada época, de um determinado pensamento. O que se faz aqui é colocar em xeque esses valores $e$ incluir novas perspectivas para a história literária - sobretudo, se questiona a história literária que se quer imanente.

Essas novas perspectivas são colocadas numa trama ideológica - como positivam o termo Kolodny e Rich - para que essa recontagem da história seja uma luta e uma disputa e se retire o valor supostamente imanente das obras literárias $e$ cinematográficas. Nesse sentido, as teorias feministas não estariam na contramão, por exemplo, do formalismo russo ou do estruturalismo, apenas radicalizando ainda mais essa luta contra a imanência do valor com uma nova perspectiva que estaria inserida dentro de um contexto ideológico. ${ }^{8}$

O feminismo, pois, não apresentaria uma ruptura total nos estudos literários ou do cânone, apenas uma nova perspectiva epistemológica e mesmo ontológica - que se soma a algumas das principais correntes teóricas do século XX: uma luta contra uma certa "aura" artística e literária. É nessa perspectiva histórica feminista que o nascimento do leitor - sobre o que Barthes falava em $A$ Morte do Autor - ganhará ainda mais destaque, já que é esse leitor o que estaria disposto a desvendar e ser coautor da obra literária e de sua história, mas também pensando sobre seu lugar de fala, de leitura e de produção crítica. Se, de certa forma, o estranhamento formalista aponta para o leitor e A Morte do Autor faz nascer o leitor, poder-se-ia ainda afirmar que esse novo leitor nasce, de fato, com a teoria feminista - um novo leitor, aqui,

8 Tanto o formalismo russo quanto o estruturalismo, ao menos em parte, apostavam ainda numa certa imanência da literatura, não da história literária. 
feminista. ${ }^{9}$ Dito isso, pode-se afirmar que, de certa forma, a teoria feminista é mais uma a problematizar a tensão entre autor e leitor.

Isso ainda é mais evidenciado já que as teorias feministas tanto do cinema quanto da literatura -, na década de 1970, ainda não se faziam como um campo totalmente autônomo, isto é, não se construíam com uma epistemologia totalmente própria, mas se utilizavam de quantas abordagens fossem interessantes para 0 desenvolvimento teórico: o que muda não são necessariamente as teorias, mas as perspectivas que se têm delas.

As teorias feministas como afirmam Kolodny, Rich, e como podemos perceber na Camera Obscura, não tentam inaugurar uma teoria sem passado, mas se utilizam de diversas correntes para que se produza uma nova forma de conhecimento. É, antes, um momento de união entre as mais diversas correntes teóricas que tomaram um viés e uma perspectiva em que estará em jogo o local da produção do conhecimento, quem é esse produtor e a própria construção da história literária e da história cinematográfica, em suma, o contexto de julgamento. Mas isso ainda não é tudo: a história literária se dinamiza de tal forma que não só se transforma o passado a partir de uma leitura do presente, como também se muda o passado a partir de uma espécie de futuro, isto é, de uma perspectiva de obras que são construídas a partir dali.

\section{Referências bibliográficas}

BARTHES, Roland. A morte do autor. In: BARTHES, Roland. O rumor da língua. São Paulo, Martins Fontes, 2004, pp.65-70.

CAMERA Obscura Collective. Feminism and Film: Critical Approaches. Camera Obscura, vol. 1, no 1, outono 1976, pp.3-10.

ChICAGO, Judy. The Dinner Party: From Creation to Preservation. Londres, Merrell, 2007.

\footnotetext{
9 Novos leitores ainda nascem a partir dos anos de 1970 dentro de outras correntes teóricas irmãs: teoria queer, black theory, teoria pós-colonialista, enfim, os leitores tidos como subalternos, para utilizar o termo de Spivak.
} 
DUARTE, Constância Lima. Nos primórdios do feminismo brasileiro. In: AugustA, Nísia Floresta Brasileira. Direito das mulheres e injustiça dos homens. São Paulo, Cortez, 1989, pp.38-41.

Elıot, T. S. Tradição e Talento Individual. In: ElıOT, T. S. Ensaios. São Paulo: Art Editora, 1989. [Trad. Ivan Junqueira]

FISHER, Caitlin. Feminist Digital Aesthetics: The Everyday and Yesterday. In: LORD, Susas; MARCHESSAULT, Janine (ed.). Fluid Screens, Expanded Cinema. Torondo, Buffalo \& Londres; University of Toronto Press, 2008, pp.145-159.

HANNA, Kathleen; BIKINI, Kill. Riot Grrrl Manifesto. In: FREEDMAN, Estelle B. The Essential Feminist Reader. Nova Iorque, The Modern Library, 2007, pp. 394-396.

Kolodny, Annette. Dancing Through the Minefield. In: HeRnd, Diane Price; WARHOL, Robyn R. Feminisms. Hampshire, Macmillan Press, 1997, pp.171-190.

MALARD, Letícia. José Veríssimo: Crítico Literário. In: AmARAL, Sérgio Alcides Pereira do et alii. A Crítica Literária Brasileira em Perspectiva. Cotia, Ateliê Editorial, 2013, pp.111-118.

MoI, Toril. Teoría Literaria Feminista. Madri, Cátedra, 1995.

MuZART, Zahidé Lupinacci (org). Escritoras Brasileiras do Século XIX: Antologia. Florianópolis, Ed. Mulheres/Edunisc, 1999.

PARSONS, Lucy. Freedom, Equality \& Solidarity. Chicago, Charles H. Kerr Publishing Company, 2004.

QUEIROZ, Vera. Crítica Literária e Estratégia de Gênero. Niterói, EDUFF, 1997.

RICH, B. Ruby. Chick Flicks. Durham, Duke University Press, 2004.

RochA, João Cezar de Castro. Sílvio Romero: A Polêmica como Sistema? In: AmARAL, Sérgio Alcides Pereira do et alli. A Crítica Literária Brasileira em Perspectiva. Cotia, Ateliê Editorial, 2013, pp.95-110.

SANDERS, Valerie. First Wave Feminism. In: GAmBlE, Sarah. Feminism and Postfeminism. Nova Iorque, Routledge, 2000, pp.16-28. 